\title{
English as a Foreign Language (EFL) Learners' Predominant Language Use for Online Informal Learning Activities through Smartphones in Indonesian Context
}

\author{
Gede Eka Putrawan*, Bambang Riadi \\ Department of Language Education and Arts, Lampung University, Indonesia
}

Received October 30, 2019; Revised December 5, 2019; Accepted February 2, 2020

\begin{abstract}
Copyright $\odot 2020$ by authors, all rights reserved. Authors agree that this article remains permanently open access under the terms of the Creative Commons Attribution License 4.0 International License
\end{abstract}

\begin{abstract}
In recent years, researchers have become increasingly interested in mobile-assisted language learning (MALL) studies for online informal learning of English as a foreign language (EFL). Smartphones, and other mobile devices, have been used as a powerful tool in informal contexts of learning since that form of technology can help students engage in out-of-class language learning experiences. However, to our knowledge, no research on EFL learners' predominant language use for their online informal learning activities has been conducted in Indonesian context. Therefore, this study attempted to investigate EFL learners' predominant language use for their online informal learning of English through smartphones, in which the data collected were quantitatively analyzed through descriptive statistics. The results indicate that EFL learners predominantly perform their online informal learning activities in Indonesian, in English, and in both Indonesian and English. Finally, suggestions and recommendations for future research are also discussed.
\end{abstract}

Keywords Online Informal Learning of English, Informal Learning, Mobile-Assisted Language Learning, Smartphones, Online Language Use

\section{Introduction}

In recent years, researchers have become increasingly interested in mobile-assisted language learning (MALL) studies for online informal learning of English as a foreign language (EFL). The use of mobile devices, such as a smartphone, has been part of people's daily life, the younger generation in particular [1], [2] and this device will probably be still in existence in the foreseeable future [3].

Smartphones, and other mobile devices, have been used as a powerful tool in both formal and informal contexts of learning [4]. They are used for informal learning in support of the formal learning and personal development [5] and most of students have considerable experiences of informal learning with their mobile devices [6]. In other words, technology helps them learn more autonomously [7].

Technology is used in informal learning context to help students engage in out-of-class language learning experiences [8]. Studying outside the classroom through smartphones is "the richest vein of language learning potential, in that students may be engaging in multiple forms of informal learning: incidental (e.g., gameplay), instrumental (e.g., use of a language learning service or app), or accidental (e.g., code-switching in a YouTube video)" [3, p. 5]. Through this type of audiovisual technology, sources of authentic language input for either formal or informal learning can be easily found by learners of both English as a second language (ESL) and a foreign language (EFL) [9].

Students perform online informal activities and use a more predominant language either English or their mother tongue for online use through their smartphones [10]. The online informal activities through smartphones are performed in their mother tongue, in English, and in both mother tongue and English at the same time [10]. The majority of the Internet users in the EU use a language other than their own for online activities such as reading, watching, and writing [11]. Although a considerable amount of research has been done, but little research has 
focused on learners' language preferences for their online informal learning of English. Moreover, to our knowledge no research on EFL learners' predominant language use for their online informal learning activities has been conducted in Indonesia. Hence, a survey on this issue was desirable to carry out in Indonesian EFL context.

\section{Literature Review}

\subsection{Online Informal Learning of English}

The Online Informal Learning of English (OILE) refers to "a complex range of internet-based activities" in which the term "informal learning" itself refers to "the way in which exposure to English outside the classroom may lead to the acquisition of the language" [12, pp. 7-8]. In this case, the online informal learning of English takes place naturalistically in which learners make use of internet-based resources which are not specifically created for educational purposes outside the classroom unconsciously [12].

\subsection{Smartphones and Online Informal Learning}

Smartphones and the Internet have nowadays become part of people's daily lives. The technologies lead to changes in "communication patterns as well as English language use" [13, p. 1] and they offer an excellent opportunity for foreign language learning [14]. Learners can perform online communication and get entertainment and information without a considerable amount of effort which costs little money [13]. Mobile devices either PDAs or smartphones have been extensively used in informal learning context [4] since a variety of online contexts such as the use of social media, games, songs and videos can support language teaching and learning [15] and "the less constrained informal learning leads to enjoyment which is positively related to the learning outcome" [16, p. 9].

A mobile device makes language learning experiences more immersive [17] that it has an influence on the way one learns a second language [18]. Young learners do a wide range of online informal learning of English (OILE) activities to be more competent in English because they have high global motivation [19] and they have a positive experience when learning English reading and grammar skills through mobile phones [20]. A web-based mobile application helps students improve their English grammar and the second language (L2) writing outside the classroom [21]. Online audiovisual-based informal EFL learning helps learners increase their speaking proficiency [22]. Learners learn English from YouTube with the aims of getting more resources and searching for more attractions for their English learning as well as discovering cultural knowledge. This way of English learning is more interesting, flexible, and interactive than formal learning conducted in the classroom [23] which indicates that engaging in a wide range of online informal activities supports the learners in learning a language [24].

\subsection{Language Use for Online Informal Learning}

Bybee (2010) and Ellis (2006) as cited in [10, p. 29] state "language constructions are sensitive to frequency, recency, and contexts of occurrence." The language constructions can be significantly increased through "online resources and interfaces" through smartphones [10, p. 29].

According to [11] most of the Internet users are reported using a language which is not their own for their online activities such as reading, watching, and writing. $[10$, p. 33] found that online informal activities can be classified into three categories which include "activities with a highly predominant use of the mother tongue, activities with a highly predominant of English, and activities where the mother tongue and English are used by similarly large numbers of participants."

\section{Methods}

To date no research on EFL learners' predominant language use for their online informal learning activities has been conducted in Indonesian context. Therefore, the present study sought to address the following research question: (1) What is EFL learners' predominant language use for online informal learning of English through smartphones in a public university in Indonesia?

\subsection{Participants}

A total of 87 undergraduate students studying English as a foreign language in a public university in Indonesia participated in this study. A total of 75 participants were female (86.2\%), 12 (13.8\%) participants were male. On average, they were 19.4 years old (the youngest was 17 and the oldest 23).

\subsection{Instrument and Data Analysis}

The participants under investigation were required to fill out a questionnaire developed by [10] to investigate either Indonesian, English or Indonesian and English was chosen for their online informal learning activities involving language use through smartphones. The questionnaire which consists of 31 statements was translated into Indonesian in order for the participants found it much easier to understand each statement. A colleague with a doctorate degree who was highly proficient in both Indonesian and English was invited to review the Indonesian version for readability, clarity, and naturalness.

A pilot survey to 20 EFL learners was conducted to make sure all information provided to all participants were clear, understandable, and reasonable in length that participants were enthusiastic to complete each statement [25]. It is also called a pre-testing, trying out the 
questionnaire before it was distributed to the participants to ensure and assess its design, its appropriateness to the participants, and if it could achieve the aim of this study [26].

The data collected in this study were quantitatively analyzed through descriptive statistics by using SPSS 23 for Windows, which was used to measure the responses of the participants to the instrument on their use of language in online informal learning activities. The patterns were examined through frequency within the whole participants in this study.

The online informal learning activities were classified into three categories including activities involving a predominant use of Indonesian or mother tongue, activities involving a predominant use of English, and activities involving both Indonesian and English which were used in a similar way by a large number of participants under investigation.

\section{Results and Discussion}

With regard to the participants' predominant language use for online informal learning activities through smartphones, their responses to the questionnaire items were computed through descriptive statistics. Their online activities are divided into three categories: online informal learning activities with a predominant use of Indonesian (mother tongue), online informal learning activities with a predominant use of English, and online informal learning activities in which both Indonesian and English are used in a similar way by the participants, as shown in Table 1 as follows.

Table 1. Predominant language use for online informal learning activities through smartphones $(n=87)$

\begin{tabular}{|c|c|c|c|}
\hline & Indonesian & English & Indonesian and English \\
\hline & \multicolumn{3}{|c|}{$\%$ of users } \\
\hline Listening to the radio & 85.1 & 8 & 6.9 \\
\hline Leaving voice messages to other users & 75.9 & 3.4 & 20.7 \\
\hline Watching television & 74.7 & 2.3 & 23 \\
\hline Communicating with my classmates regarding study-related issues & 67.8 & 4.6 & 27.6 \\
\hline Keeping a blog & 60.9 & 16.1 & 23 \\
\hline Keeping an audio/audio-visual blog & 60.9 & 12.7 & 26.4 \\
\hline Writing emails & $\mathbf{5 7 . 5}$ & 8 & 34.5 \\
\hline Listening to podcasts & 51.7 & 20.7 & 27.6 \\
\hline Checking non-study related information & 50.6 & 14.9 & 34.5 \\
\hline Reading the daily news & 50.6 & 11.5 & 37.9 \\
\hline Playing games that require spoken communication with other players & 48.3 & 18.4 & 33.3 \\
\hline Writing short text messages (WhatsApp, SMS, WeChat, etc.) & 47.1 & 1.1 & 51.8 \\
\hline $\begin{array}{l}\text { Participating in LinkedIn, Facebook, and other online groups that talk about } \\
\text { language learning }\end{array}$ & 44.8 & 26.4 & 28.8 \\
\hline Posting social media comments & 40.2 & 13.8 & 46 \\
\hline Listening to audio books & 37.9 & 36.8 & 25.3 \\
\hline Playing games that require written communication with other players & 36.8 & 19.5 & 43.7 \\
\hline Reading emails & 35.6 & 26.4 & 38 \\
\hline Reading long texts & 35.6 & 13.8 & 50.6 \\
\hline Reading social media comments & 32.2 & 14.9 & 52.9 \\
\hline Looking for study-related information & 27.6 & 26.4 & 46 \\
\hline Communicating with my teachers regarding study-related issues & 26.4 & 25.3 & 48.3 \\
\hline Reading e-books & 24.1 & 31 & 44.9 \\
\hline Watching short clips with text & 21.8 & 40.2 & 38 \\
\hline Playing language games such as crosswords & 21.8 & 51.8 & 26.4 \\
\hline Accessing websites with language learning exercises & 18.4 & 58.6 & 23 \\
\hline Playing games that require reading instructions & 17.2 & 59.8 & 23 \\
\hline Writing down new words that I learn in a foreign language & 11.5 & 60.9 & 27.6 \\
\hline Listening to lectures & 9.2 & 31 & 59.8 \\
\hline Using language learning apps that I have downloaded onto my smartphone & 8 & 66.7 & 25.3 \\
\hline Listening to music & 1.1 & 55.2 & 43.7 \\
\hline Accessing online dictionaries & 0 & 62.1 & 37.9 \\
\hline
\end{tabular}


Indonesian, which is the participants' mother tongue, is still predominantly used for online informal learning activities through smartphones. These online activities include listening to the radio $(85.1 \%)$, leaving voice messages to other users $(75.9 \%)$, watching television (74.7\%), communicating with classmates regarding study-related issues (67.8\%), keeping a blog (60.9\%), keeping an audio-visual blog $(60.9 \%)$, writing emails $(57.5 \%)$, and listening to podcasts $(51.7 \%)$.

English is predominantly used for some online activities which include using language learning apps downloaded onto smartphones $(66.7 \%)$, accessing online dictionaries $(62.1 \%)$, writing down new words learned in a foreign language $(60.9 \%)$, playing games that require reading instructions $(59.8 \%)$, accessing websites with language learning exercises (58.6\%), listening to music $(55.2 \%)$, and playing language games $(51.8 \%)$.

Finally, some online activities through smartphones are also performed in both Indonesian and English including listening to lectures $(59.8 \%)$, reading social media comments $(52.9 \%)$, and writing short text messages $(51.8 \%)$.

This article was aimed at investigating the predominant language use for online informal learning of English performed by EFL undergraduate learners in Indonesian context. The findings in this study confirm that English is not the predominant language used by undergraduate EFL learners which is in line with Jurkovič's findings [10]. For example, they predominantly use Indonesian, their mother tongue, when listening to the radio, leaving voice messages to other users, and watching television. In other words, their smartphones are not utilized for online activities of EFL informal learning to a maximum extent, whereas the technology can actually help them position themselves as "authentic English users and not only as students of the language" [27, p. 148].

Most of the participants use English to perform online activities such as using language learning applications, accessing online dictionaries, writing down new words in a foreign language, playing games with reading instructions, accessing websites with language learning exercises, and playing language games. In addition, most of them listen to English music, which is in line with findings in other contexts [10].

Other online activities are also performed in both Indonesian and English in a similar way. In other words, on some occasions the online activities through their smartphones are performed in Indonesian and on some other occasions in English. The activities include listening to lectures, reading social media comments, and writing short text messages.

\section{Conclusions}

The findings in this study have provided fascinating insights into EFL learners' predominant language use for online informal learning activities through smartphones in Indonesian context. The participants predominantly perform the activities in Indonesian, in English, and in both Indonesian and English in a similar way. Therefore, this study implies that consideration to integrate informal learning activities in formal instructional settings should be taken into account [27]. For example, encouraging online activities between students and teacher through Facebook using appropriate interactions design to make learning more fun and meaningful [28], especially EFL learning activities. It is a potential application for both teaching and learning [29].

However, this study is not without its limitations. This study was conducted in a small sample size $(n=87)$, therefore, larger number of participants are required by further research in other contexts where English is a foreign language. In addition, to provide more reliable findings, more advanced quantitative analysis equipped with qualitative analysis should be undertaken by future researchers.

\section{Acknowledgments}

The authors would like to express their gratitude to all respondents who participated in the present study. We are also very grateful to experts for their appropriate and constructive suggestions to improve this paper.

\section{REFERENCES}

[1] F. AlTameemy, "Mobile phones for teaching and learning," J. Educ. Technol. Syst., vol. 45, no. 3, pp. 436-451, 2017.

[2] A. Razzaq, Y. T. Samiha, and M. Anshari, "Smartphone habits and behaviors in supporting students self-efficacy," Int. J. Emerg. Technol. Learn., vol. 13, no. 2, pp. 94-109, 2018.

[3] R. Godwin-Jones, "Smartphones and language learning," Lang. Learn. Technol., vol. 21, no. 2, pp. 3-17, 2017.

[4] G. Clough, A. C. Jones, P. McAndrew, and E. Scanlon, "Informal learning with PDAs and smartphones," J. Comput. Assist. Learn., vol. 24, no. 5, pp. 359-371, 2008.

[5] K. W. Lai and L. A. Smith, "Tertiary students' understandings and practices of informal learning: A New Zealand case study," Australas. J. Educ. Technol., vol. 33, no. 2, pp. 115-128, 2017.

[6] M. Kondo, Y. Ishikawa, C. Smith, K. Sakamoto, H Shimomura, and N. Wada, "Mobile Assisted Language Learning in university EFL courses in Japan: Developing attitudes and skills for self-regulated learning," ReCALL, vol. 24, no. 2, pp. 169-187, 2012.

[7] C. Lai, "Technology and Learner Autonomy: An Argument in Favor of the Nexus of Formal and Informal Language 
Learning,” Annu. Rev. Appl. Linguist., vol. 39, pp. 52-58, 2019.

[8] C. Lai and M. Gu, "Self-regulated out-of-class language learning with technology," Comput. Assist. Lang. Learn., vol. 24, no. 4, pp. 317-335, 2011.

[9] T. Bahrani, T. S. Sim, and M. Nekoueizadeh, "Second language acquisition in informal setting," Theory Pract. Lang. Stud., vol. 4, no. 8, pp. 1714-1723, 2014.

[10] V. Jurkovič, "Online informal learning of English through smartphones in Slovenia," System, vol. 80, pp. 27-37, 2019.

[11] Commission European, "User language preferences online,' Hungary, 2011.

[12] G. Sockett, The Online Informal Learning of English. New York: Palgrave Macmillan, 2014.

[13] R. Trinder, "Informal and deliberate learning with new technologies," ELT J., vol. 71, no. 4, pp. 401-412, 2017.

[14] A. Alsanosi, A. Aharbi, and S. Alhebaishi, "Smart device usage frequency and usage level for learning English," Int. J. Emerg. Technol. Learn., vol. 14, no. 19, pp. 49-64, 2019.

[15] G. Kessler, "Technology and the future of language teaching," Foreign Lang. Ann., vol. 51, no. 1, pp. 205-218, 2018.

[16] R. Panigrahi, P. R. Srivastava, and D. Sharma, "Online learning: Adoption, continuance, and learning outcome-A review of literature," Int. J. Inf. Manage., vol. 43, no. July 2016, pp. 1-14, 2018.

[17] M. Ali and S. K. Miraz, "Mobile assisted language learning (MALL) - A brief survey," Ann. Emerg. Technol. Comput., vol. 2, no. 2, pp. 37-45, 2018.

[18] S. Loewen et al., "Mobile-assisted language learning: A Duolingo case study," ReCALL, pp. 1-19, 2019.

[19] M. Lamb and F. E. Arisandy, "The impact of online use of English on motivation to learn," Comput. Assist. Lang. Learn., vol. 0, no. 0, pp. 1-24, 2019.

[20] S. Wang and S. Smith, "Reading and grammar learning through mobile phones," Lang. Learn. Technol., vol. 17, no. 3, pp. 117-134, 2013.

[21] Z. Li and V. Hegelheimer, "Mobile-assisted grammar exercises: Effects on self-editing in L2 writing," Lang. Learn. Technol., vol. 17, no. 3, pp. 135-156, 2013.

[22] T. Bahrani and T. S. Sim, "Informal language learning setting: Technology or social interaction?," Turkish Online J. Educ. Technol., vol. 11, no. 2, pp. 142-149, 2012.

[23] H. Wang and C. W. Chen, "Learning English from YouTubers: English L2 learners' self-regulated language learning on YouTube," Innov. Lang. Learn. Teach., pp. $1-14,2019$.

[24] A. Van Marsenille, "Informal learning activities for learners of English and for learners of Dutch," in Beyond the language classroom: researching MOOCs and other innovations, Q. Kan and S. Bax, Eds. Research-publishing.net, 2017, pp. 141-152.
[25] E. Schleef, "Written surveys and questionnaires in sociolinguistics," in Research methods in sociolinguistics: A practical guide, First., John Wiley \& Sons, Inc., 2014, pp. $42-57$.

[26] P. M. McQuirk and P. O’Neill, "Using questionnaires in qualitative human geography," in Qualitative Research Methods in Human Geography, I. Hay, Ed. Don Mills, Canada: Oxford University Press, 2016, pp. 246-273.

[27] G. Sockett and D. Toffoli, "Beyond learner autonomy: A dynamic systems view of the informal learning of English in virtual online communities," ReCALL, vol. 24, no. 2, pp. 138-151, 2012.

[28] N. F. Jumaat, N. Ahmad, N. Abu Samah, Z. M. Ashari, D. F. Ali, and A. H. Abdullah, "Facebook as a platform of social interactions for meaningful learning," Int. J. Emerg. Technol. Learn., vol. 14, no. 4, pp. 151-159, 2019.

[29] T. E. Bosch, "Using online social networking for teaching and learning: Facebook use at the university of cape town," Communicatio, vol. 35, no. 2, pp. 185-200, 2009. 